\title{
Exchange Rate and Central Bank Intervention
}

\section{Wong Hock Tsen*}

School of Business and Economics, Universiti Malaysia Sabah, Malaysia

Exchange rate and central bank intervention is an important topic in the exchange rate determination [1-4]. Exchange rates are volatile after the breakdown of the Bretton Woods system of fixed exchange rate in the year 1973. Central banks especially those in economies adopted a managed exchange rate regime actively intervene in the exchange rate market to maintain their exchange rates and to reduce their exchange rate volatility, which can affect international trade, financial flow and economic growth. Central bank intervention in the exchange rate market may want to accrue international reserves to enhance the fundamental of the economy [5]. There are two important issues related to the exchange rate intervention, namely the effectiveness of central bank intervention and the success of central bank in maintaining the exchange rate and in reducing exchange rate volatility $[1,4,6]$. In general, the literature of exchange rate and central bank intervention is inconclusive on the impact of central bank intervention. Most studies conclude that central bank intervention tends to increase exchange rate volatility [4].

Japan vigorously purchased the United States dollar (USD) in the exchange rate market to deter the appreciation of the Japanese yen (JPY) in the 1990s [6,7]. A strong currency could retard economic growth. [7] evaluate the effectiveness of central bank intervention in Japan using an autoregressive-exponential general autoregressive conditional heteroskedastic (AR-EGARCH) model, more specifically the AR-EGARCH $(1,1)$ model. The data are daily from May 13, 1991 to March 16, 2004. The results show that secret interventions were ineffective in affecting the JPY in the post-1995 period. However, those interventions were effective in reducing exchange rate volatility. When central bank camouflaged its transactions, interventions proved to be effective in affecting both the JPY trend and volatility. Central bank interventions were more effective in moving exchange rate in the desired direction if they were combined with oral interventions. Secret interventions during oral intervention periods were effective in reducing exchange rate volatility. There are many reasons for secret intervention. A secret intervention is used to correct a current trend in exchange rate, which is contradicted with the monetary policy objective. Thus a secret intervention can achieve the exchange rate aim without losing the monetary policy credibility. Central bank without credibility might achieve desired outcomes with a secret intervention. A secret intervention would reduce exchange rate volatility [7].

Douglas et al. [8] explore the motive of central bank intervention in the exchange rate market in Japan using two dynamic binary choice models, namely the autoregressive conditional hazard (ACH) model and the autoregressive conditional binomial (ACB) model. The ACH model is an extension of the autoregressive conditional duration (ACD) model. The ACD model estimates the time between successive events, that is, the time between an intervention today and the next intervention. The ACH model extends the ACD model to estimate the probability of an intervention conditional on the information known up to that point. The ACB model, which is a binary extension of the autoregressive conditional multinomial model, allows the probability of an intervention to depend on the past interventions and on the past response probabilities of intervention. Moreover, the ACB model nests a probity model to test the relevance of the time dynamics in central bank intervention. The daily data for the United States (US) Federal
Reserve and the German Bundesbank are from January 5, 1987 to January 22, 1993 and the daily data for the Bank of Japan are from April 1, 1991 to February 28, 2001. The results suggest that the US Federal Reserve does not intervene in response to a deviation of exchange rate from fundamental and tends to intervene when the market is calm. Conversely, the German Bundesbank intervenes in response to a deviation of exchange rate from fundamental and intervenes when the market is calm. The Bank of Japan was leaning against the wind before the Eisuke Sakakibara period whereas was leaning with the wind during the Eisuke Sakakibara period. Eisuke Sakakibara was the director general of the International Finance Bureau of the Japanese Ministry of Finance on June 1, 1995. The pre-Eisuke Sakakibara period was characterized by small and frequent central bank intervention in the exchange rate market whilst during the Eisuke Sakakibara period was characterized by large and infrequent central bank intervention in the exchange rate market $[6,8]$.

Hassan [6] investigates the effectiveness of central bank intervention in the exchange rate market in Japan using an EGARCH model. The data are daily for the period from January 2, 1992 to March 31,2004 . The sample period is characterized by three different patterns of interventions, namely frequent small, infrequent large and frequent large. Previous studies on the impact of central bank intervention in the exchange rate market in Japan divide the full period of intervention into two sub-periods. The results show central bank intervention in the exchange rate market reduces the volatility in the first period. However, the effectiveness in the first period is different from the second period and the third period. Moreover, the impact of the frequency of central bank intervention in the exchange rate market is more important on the exchange rate trend whereas it is less important on exchange rate volatility as compared to the size of intervention. A change from a small intervention to a large intervention reduces the rate of appreciation of the exchange rate by 0.01 percent. A change from perfectly frequent to perfectly infrequent interventions improves the rate of depreciation by 0.1 percent. Furthermore, small frequent intervention reduces exchange rate volatility whereas large frequent intervention increases exchange rate volatility.

Cheng et al. [4] examine the effectiveness of central bank intervention in the exchange rate market in Japan on the volatilities of the USD/JPY and Deutsche Mark (EURO) against the JPY exchange rates. The data are daily five minutes quotes for the period from April 1, 1991 to July 31, 2006. Exchange rate volatility is decomposed into

*Corresponding author: Wong Hock Tsen, School of Business and Economics, Universiti Malaysia Sabah, Malaysia, Tel: +60 88 321616; E-mail: htwong@ums.edu.my

Received February 19, 2014; Accepted February 19, 2014; Published February 26, 2014

Citation: Tsen WH (2014) Exchange Rate and Central Bank Intervention. J Glob Econ 2: e104. doi:10.4172/2375-4389.1000e104

Copyright: (c) 2014 Tsen WH. This is an open-access article distributed under the terms of the Creative Commons Attribution License, which permits unrestricted use, distribution, and reproduction in any medium, provided the original author and source are credited. 
two components, namely the smooth persistent component and the discontinuous jump component using the bi-power variation. The bipower variation is calculated based on adjacent absolute returns. The jump component of the realized volatility is consistently estimated by the difference between the realized volatility and bi-power variation. One advantage of separating the smooth persistent volatility component and less persistent jump process is that it can better describe in-sample exchange rate processes and provides out of sample forecast accuracy. Exchange rate returns, the different components of volatility and central bank intervention are modeled in the simultaneous equations. The use of the simultaneous equations is to address the problem of endogeneity of variables used in the estimation. The results show that central bank intervention increases both the continuous and the jump components of daily volatility. There is no evidence that interventions are effective in influencing the exchange rate returns for the entire sample period. Central bank is unsuccessful in stabilizing the daily realized volatilities in the exchange rate market.

There are many studies examine the impact of central bank intervention on spot exchange rate but relatively not many studies investigate the correlation between central bank intervention and currency options. [1] Focus on the co-movements of exchange rates around central bank interventions in Japan. More specifically, this study analyses the effects of central bank intervention in selling the JPY on the ex-ante correlations between exchange rates. These exante correlations implied by currency options may be regarded as the market expectation of the degree of future co-movements between two exchange rates over the remaining life of the option contracts. Thus it is interesting to examine whether the expected exchange rate co-movements are affected by central bank interventions. The implied correlations are extracted from currency options traded in the over-the-counter markets, which consist daily one-month and three-month implied volatility of options on the JPY/USD, EURO/ USD, British Pounds/USD, JPY/EURO, JPY/British Pounds exchange rates. The data are from October 1, 2001 to June 30, 2005. The results show that central bank interventions significantly affect the market expectations about the future exchange rate co-movements. Implied exchange rate correlations increase on the first day of a period of successive intervention days. Furthermore, the size of the intervention is positively related to the change in implied correlations. However, the positive effect of interventions on implied correlations does not continue after the first intervention day. Implied correlations decrease after an intervention. The ex-ante exchange rate correlations are lower during the intervention periods than during periods with no central bank intervention.

One problem in testing central bank intervention in the exchange rate market is the limited information of central bank intervention. Thus the proxy for central bank intervention such as changes in the central bank's holdings on international reserves is used. It is argued that there is strong correlation between the central bank's holdings on international reserves and exchange rate. However, the use of changes in the central bank's holdings on international reserves as a proxy for central bank intervention remains a debate. [9] Examine the comovement between changes in international reserves and exchange rate intervention using the general autoregressive conditional heteroskedastic model. The monthly data for the US, Japanese and German are from April 1973 to December 1994, from April 1991 to March 2004 and from January 1976 to December 1995, respectively. The results show that there is a significant co-movement between central bank intervention and exchange rate in Japan and Germany. However, there is no significant co-movement between central bank intervention and exchange rate in the US. The conditional correlation dynamic between the change in international reserves and exchange rate is driven mainly by the average intervention amount, intervention frequency within any given month and the variability in the intervention amount. There is evidence of correlation asymmetry in purchases as opposed to sales of the USD intervention. Nonetheless, there is no evidence of correlation asymmetry is found for in Japan and Germany. Having controlled for macroeconomic factors in explaining changes in international reserves, there is substantial improvement in the comovement between changes in international reserves and intervention activity in the US. The central bank's holdings on international reserves are good proxy for the exchange rate market intervention.

Central bank intervention is not randomly but likely is implemented strategically. An exchange rate at a given of time concurs with intervention or no intervention. Thus it cannot be identified both what is the exchange rate movement corresponding with intervention and what would have been the counterfactual, that is, what would be to exchange rate when intervention is not occurred when in fact it is happened. The counterfactual is not directly observable and this is a missing data problem [10]. Fatum et al. [10] estimate the counterfactual exchange rate movement in the absence of intervention using the method of propensity-score matching to estimate the average treatment effect of intervention. The matching method addresses the issue of non-random sample selection. The data are daily JPY/USD exchange rates for the period from January 1, 1999 to March 31, 2004. The results show that sporadic and relatively infrequent intervention, that is, from the period from 1999 to 2002 is effective whereas frequent and large-scale intervention, that is, from the period from 2003 to 2004 is ineffective.

There are not many studies explore the link between central bank intervention and exchange rate spread. Fatum, Pedersen et al. [11] analyze central bank intervention in the Danish Krone-EURO (DKK/ EURO) exchange rate bid-ask spread in the Exchange Rate Mechanism of the European Union. The data are daily five minutes spot bid and ask of the DKK/EURO for the period from August, 12002 to December, 312004 . The ordinary least squares with hetero skedasticity and autocorrelation consistent standard errors and covariance's estimator and the weighted least squares estimator are used. The results show that failure to allow for the asymmetric affects across intervention purchases and intervention sales can lead to failure to detect the influence of intervention. Intervention purchases and sales both significantly influence the spread but the direction of the intervention matters for the resolution of uncertainty in the market. Intervention purchases of currency reduce the spread while intervention sales of currency increase the spread [11].

There is an extensive literature unearth the link between exchange rate and order flow in the exchange rate market. Interbank order flows into a currency tend to appreciate that currency. However, changes in the exchange rate are notably hard to explain. Marsh [3] investigates whether the actions of the Bank of Japan to deter the value of the JPY affected the behavior of customers of a major European commercial bank. The data are daily end-user order flow of spot exchange rate for the period from August 1, 2002 to March 2, 2006. The results show that limited evidence is found that corporate customers are more than usually likely to be net sellers of the JPY on days when the Bank of Japan is intervening to sell the JPY. However, there is somewhat stronger evidence that financial customers are more likely to be net buyers of the JPY on the same days. Moreover, very clear evidence is found that intervention matters in a microstructure analysis. The significant 
correlation between order flows and exchange rate changes disappears on days when the Bank of Japan intervenes [3].

China is argued to use international reserves to manipulate its exchange rate to take advantage of its currency from its trading partners [12]. Choi et al. [13] investigate whether an economy can benefit from generating a trade deficit or surplus by arbitrarily changing the reminding against the USD peg exchange rate regime. In a two-period framework, if an economy incurs a trade deficit in the first period, the principal plus interest must be paid off in the second period. If an economy accumulates a trade surplus in the first period, the investment plus interest income must be spent in the second period. Under reasonable conditions on marginal utility of income, it can be shown that the equilibrium exchange rate is the optimal exchange rate, which yields trade balances over the two periods. Trade surplus or deficit must be offset by an opposing deficit or surplus in the second period. The non-equilibrium exchange rate will yield uneven utilities and marginal utilities of income, which contribute to lower consumer welfare, provided that indirect utility is concave in expenditure. Thus the huge accumulation of the international reserves in China might suggest that the exchange rate policy can be harmful to consumer welfare.

India adopts a managed exchange rate regime. Goyal et al. [14] inspect the impact of monetary policy measures such as interest rates and intervention on exchange rate level and volatility and compare these to the impact of central bank communication (review and speeches) in dummy variables using an EGARCH model. The data are daily and monthly. The daily data are for the period from November 1, 2005 to December 31, 2008. The monthly data are for the period from January 2002 to December 2008. The daily data are used because the exchange rate market may take few days to absorb the news. The monthly data are said to pick up strategic interaction, feedback and simultaneity. The results show that variations in the EURO/USD exchange rate affect the Rupee/USD exchange rate level and volatility. The interest rate differential tends to increase variance and depreciate the Rupee/ USD exchange rate. News decreases volatility. Domestic policy variables affect both level and volatility. Communication channels have potential impact. Fry-McKibbin et al. [5] address the effects of intervention on exchange rate volatility and international reserves accumulation in Sri Lanka using a latent factor model of central bank intervention. This latent factor model captures movements that are common to all exchange rate returns, idiosyncratic to each asset and related to intervention. The use of the latent factor model provides a parsimonious representation of the data. Observable variables do not have to be identified. The latent factor model admits the decomposition of exchange rate returns into the contribution that each of the factors makes to overall volatility. The data are daily for the period from January 1, 2002 to December 31, 2010. In the low volatility period in the first part of the sample, the central bank is successful in influencing currency when pressure is to appreciate, accumulating international reserves. The same model estimated for the global volatility period in the second part of the sample shows the central bank intervening to mitigate excessive exchange rate volatility in line with the short-run objective. The results indicate that intervention of an emerging market may affect the currency markets of neighboring emerging markets. Therefore it is important to take into account the cross currency market interdependence between emerging markets.

Emerging market economies are argued to be intervened in the exchange rate market more often than developed economies. Thus the conclusion of central bank interventions in emerging market economies may be different from those in developed economies. Broto [15] investigates central bank interventions in the exchange rates markets in four Latin American economies with inflation targets, namely Chile, Colombia, Mexico and Peru. Emerging market economies adopt inflation targets tend to intervene frequently in the exchange rate market, which will result greater vulnerability in the exchange rate market [16]. The daily returns of the USD against the Chilean peso, the Colombian peso, the Mexican peso and the Peruvian nuevo sol for the periods from January 1, 2004 to June 15, 2011, from January 3, 2000 to June 30, 2011, from July 31, 1996 to June 6, 2011 and from February 1, 2000 to June 3, 2011, respectively are used. The results show that central bank interventions in all economies but Chile, where interventions are rule-based, have an asymmetric effect on the conditional variance. There is no homogeneous pattern across economies regarding which type of interventions. It is easier to determine which interventions, in terms of frequency and size, impact on the exchange rate level and volatility in the desired direction. The intervention size plays a minor role in influencing the exchange rate.

On the whole, there is an extensive literature on the role of central bank intervention in the exchange rate determination. In general, there is no consensus on the impact of central bank intervention on exchange rate. This conclusion is hold for developed, developing or emerging economies. Nevertheless, it is believe that central bank intervention in the exchange rate market tends to increase exchange rate volatility. The availability of high frequency data such as intraday or daily data permits central bank intervention and exchange rate to be examined more precisely. There are various estimation methods such as the EGARCH model used to examine the link between central bank intervention and exchange rate. There are many issues have been addressed related to the impact of central bank interventions on exchange rate such as the impact of central bank interventions on option-implied exchange rate correlations. The proxy for central bank intervention such as the changes in the central bank's holdings on international reserves is tested. The changes in the central bank's holdings on international reserves can be good proxy for intervention activity in the absence of official central bank intervention data. There is a relationship between central bank intervention and exchange rate spread. Interbank order flows into a currency tend to appreciate that currency. Thus there is link between central bank intervention and exchange rate. Perhaps, there are no gains from central bank intervention in manipulating exchange rate in the long run. In short, there are many more issues related to central bank intervention and exchange rate to be implemented at macro and micro levels.

\section{References}

1. Nikkinen J, Vähämaa $S$ (2009) Central bank interventions and implied exchange rate correlations. J Empirical Financ 16: 862-873.

2. Lee HY (2011) Nonlinear exchange rate dynamics under stochastic officia intervention. Econ Model 28: 1510-1518.

3. Marsh IW (2011) Order flow and central bank intervention: An empirica analysis of recent Bank of Japan actions in the foreign exchange market. J Int Money Financ 30: 377-392.

4. Cheng A, Das K, Shimatani T (2013) Central bank intervention and exchange rate volatility: Evidence from Japan using realized volatility. J Asian Econ.

5. Fry-McKibbin RA, Wanaguru S (2013) Currency intervention: A case study of an emerging market. J INT MONEY FINANC 37: 25-47.

6. Hassan M (2012) Japanese foreign exchange intervention: A tale of pattern size, or frequency. Jpn World Econ 24: 184-192.

7. Kim SJ, Le AT (2010) Secrecy of Bank of Japan's yen intervention: Evidence of efficacy from intra-daily data. J JPN INT ECON 24: 369-394.

8. Douglas CC, Kolar M (2009) Capturing the time dynamics of central bank intervention. J Int Financ Markets, Institutions and Money 19: 950-968. 
9. Suardi S, Chang $Y$ (2012) Are changes in foreign exchange reserves a good proxy for official intervention? J Int Financ Markets, Institutions and Money 22: 678-695.

10. Fatum R, Hutchison MM (2010) Evaluating foreign exchange market intervention: Self-selection, counterfactuals and average treatment effects. J Int Money Financ.

11. Fatum R, Pedersen J, Sørensen PN (2013) The intraday effects of central bank intervention on exchange rate spreads. J Int Money Financ 33: 103-117.

12. Jin H, Choi EK (2013) Profits and losses from currency intervention. Int Rev Econ \& Financ 27: 14-20.
13. Choi EK, Jin H (2014) Currency intervention and consumer welfare in an open economy. Int Rev Econ \& Financ 29: 47-56.

14. Goyal A, Arora S (2012) The Indian exchange rate and central bank action: An EGARCH analysis. J Asian Econ 23: 60-72.

15. Broto C (2013) The effectiveness of forex interventions in four Latin American countries. EMERG Markets Rev 17: 224-240.

16. Berganza JC, Broto $C$ (2012) Flexible inflation targets, forex interventions and exchange rate volatility in emerging countries. J Int Money Financ 31: 428-444. 